Cochrane Database of Systematic Reviews

\title{
Conservative management of oesophageal soft food bolus impaction (Review)
}

Hardman J, Sharma N, Smith J, Nankivell P

Hardman J, Sharma N, Smith J, Nankivell P.

Conservative management of oesophageal soft food bolus impaction.

Cochrane Database of Systematic Reviews 2020, Issue 5. Art. No.: CD007352.

DOI: 10.1002/14651858.CD007352.pub3.

www.cochranelibrary.com 
TABLE OF CONTENTS

HEADER 1

ABSTRACT

PLAIN LANGUAGE SUMMARY

SUMMARY OF FINDINGS

BACKGROUND

OBJECTIVES

METHODS

Figure 1.

RESULTS

DISCUSSION

AUTHORS' CONCLUSIONS

ACKNOWLEDGEMENTS

REFERENCES

CHARACTERISTICS OF STUDIES

DATA AND ANALYSES

Analysis 1.1. Comparison 1: Diazepam and glucagon compared to placebo for the management of impacted food bolus in the oesophagus, Outcome 1: Disimpaction

APPENDICES

WHAT'S NEW

HISTORY

CONTRIBUTIONS OF AUTHORS

DECLARATIONS OF INTEREST

DIFFERENCES BETWEEN PROTOCOL AND REVIEW

INDEX TERMS 
[Intervention Review]

\title{
Conservative management of oesophageal soft food bolus impaction
}

\author{
John Hardman¹, Neil Sharma2,3, Joel Smith4, Paul Nankivell5,6 \\ 1Head and Neck Unit, The Royal Marsden Hospital, London, UK. 2Department of Otolaryngology, Head and Neck Surgery, University \\ Hospitals Birmingham, Birmingham, UK. 3 Institute of Cancer and Genomic Studies, University of Birmingham, Birmingham, UK. \\ ${ }^{4}$ Department of Otolaryngology, Head and Neck Surgery, Royal Devon and Exeter Hospital, Exeter, UK. ${ }^{5}$ Department of Otolaryngology, \\ Head and Neck Surgery, Queen Elizabeth Hospital, Birmingham, UK. GInstitute of Head and Neck Studies and Education, Institute of \\ Cancer and Genomic Studies, University of Birmingham, Birmingham, UK
}

Contact address: John Hardman, johnchardman@gmail.com.

Editorial group: Cochrane Upper GI and Pancreatic Diseases Group.

Publication status and date: New, published in Issue 5, 2020.

Citation: Hardman J, Sharma N, Smith J, Nankivell P. Conservative management of oesophageal soft food bolus impaction. Cochrane Database of Systematic Reviews 2020, Issue 5. Art. No.: CD007352. DOI: 10.1002/14651858.CD007352.pub3.

Copyright ( 2020 The Cochrane Collaboration. Published by John Wiley \& Sons, Ltd.

\section{A B S T R A C T}

\section{Background}

Impaction of a soft food bolus in the oesophagus causes dysphagia and regurgitation. If the bolus does not pass spontaneously, then the patient is at risk of aspiration, dehydration, perforation, and death. Definitive management is with endoscopic intervention, recommended within 24 hours. Prior to endoscopy, many patients undergo a period of observation, awaiting spontaneous disimpaction, or may undergo enteral or parenteral treatments to attempt to dislodge the bolus. There is little consensus as to which of these conservative strategies is safe and effective to be used in this initial period, before resorting to definitive endoscopic management for persistent impaction.

\section{Objectives}

To evaluate the efficacy of non-endoscopic conservative treatments in the management of soft food boluses impacted within the oesophagus.

\section{Search methods}

We searched the following databases, using relevant search terms: Cochrane Central Register of Controlled Trials (CENTRAL), MEDLINE, Embase and CINAHL. The date of the search was 18 August 2019. We screened the reference lists of relevant studies and reviews on the topic to identify any additional studies.

\section{Selection criteria}

We included randomised controlled trials of the management of acute oesophageal soft food bolus impaction, in adults and children, reporting the incidence of disimpaction (confirmed radiologically or clinically by return to oral diet) without the need for endoscopic intervention. We did not include studies focusing on sharp or solid object impaction.

\section{Data collection and analysis}

We used standard methodological procedures recommended by Cochrane.

\section{Main results}

We identified 890 unique records through the electronic searches. We excluded 809 clearly irrelevant records and retrieved 81 records for further assessment. We subsequently included one randomised controlled trial that met the eligibility criteria, which was conducted in four Swedish centres and randomised 43 participants to receive either intravenous diazepam followed by glucagon, or intravenous placebos. The effect of the active substances compared with placebo on rates of disimpaction without intervention is uncertain, as the numbers from 
this single study were small, and the rates were similar (38\% versus $32 \%$; risk ratio $1.19,95 \%$ confidence interval 0.51 to $2.75, P=0.69$ ). The certainty of the evidence using GRADE for this outcome is low. Data on adverse events were lacking.

\section{Authors' conclusions}

There is currently inadequate data to recommend the use of any enteral or parenteral treatments in the management of acute oesophageal soft food bolus impaction. There is also inadequate data regarding potential adverse events from the use of these treatments, or from potential delays in definitive endoscopic management. Caution should be exercised when using any conservative management strategies in these patients.

\section{PLAIN LANGUAGE SUMMARY}

Use of treatments to dislodge soft foods stuck between the throat and the stomach to try to avoid the need for an endoscopy

\section{Review question}

Can a period of observation, treatment with swallowed substances, or treatment with substances given via the blood help to dislodge soft foods that are stuck between the throat and the stomach in order to avoid the need for an endoscopic procedure to clear it?

\section{Background}

Food can sometimes get stuck in the oesophagus, the pipe connecting the throat to the stomach that passes through the chest. This food often dislodges on its own, without any medical help, but occasionally a doctor's help is needed to clear it. Removing or dislodging these lumps of food can be done using a flexible camera or a rigid instrument, called an endoscope, but endoscopic procedures can have serious complications, like causing holes in the oesophagus. However, waiting for too long for the food to clear on its own can also increase the risk of a hole in the oesophagus and may lead to saliva or food falling into the lungs, causing serious infections. A variety of treatments are currently used to try to clear the food, without having to resort to an endoscopy, many of which also have potential side effects, including difficulty breathing, increased blood sugar levels, low blood pressure, and irregular heartbeat. We wanted to know if any of these treatments were better than simply waiting for the food to clear on its own, before trying to dislodge it with instruments.

\section{Study characteristics}

The evidence is current to August 2019. We found one trial suitable to answer our question, which compared giving a patient two drugs into a vein in (diazepam and glucagon) to placebos (clear liquids which appeared similar to the drugs but have no effect on the body). We did not look at treating sharp or hard objects, as these are treated differently.

\section{Key results}

There was not enough evidence to say with certainty which treatments for food impacted in the oesophagus are safe or effective.

\section{Quality of the evidence}

We graded the overall certainty of the evidence as low. More studies with more participants are needed to be able to answer the review question. 
SUMMARY OF FINDINGS

\section{Summary of findings 1. Diazepam and glucagon compared to placebo for the management of impacted food bolus in the oesophagus}

Diazepam and glucagon compared to placebo for the management of impacted food bolus in the oesophagus

Patient or population: management of impacted food bolus in the oesophagus

Setting: 4 Swedish ear, nose, and throat (ENT) departments

Intervention: diazepam and glucagon

Comparison: placebo

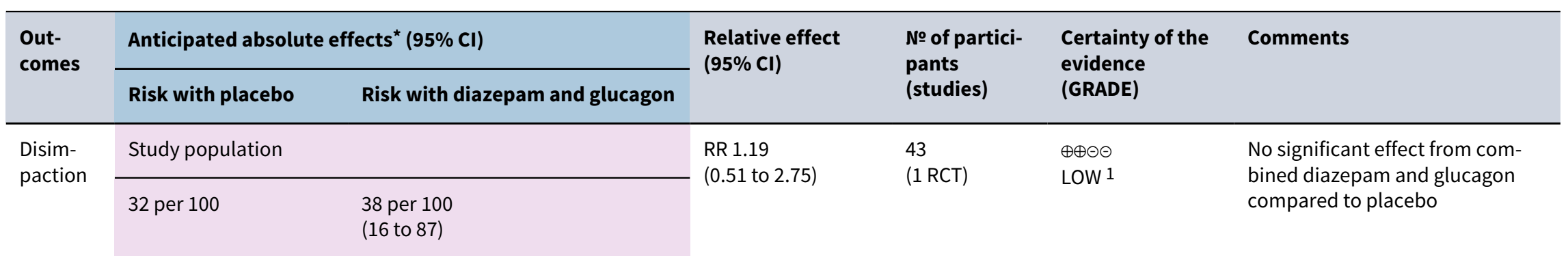

*The risk in the intervention group (and its $95 \%$ confidence interval) is based on the assumed risk in the comparison group and the relative effect of the intervention (and its $95 \% \mathrm{Cl}$ ).

Cl: confidence interval; $\mathbf{R C T}$ : randomised controlled trial; RR: risk ratio

\section{GRADE Working Group grades of evidence}

High certainty: We are very confident that the true effect lies close to that of the estimate of the effect.

Moderate certainty: We are moderately confident in the effect estimate: the true effect is likely to be close to the estimate of the effect, but there is a possibility that it is substantially different.

Low certainty: Our confidence in the effect estimate is limited: the true effect may be substantially different from the estimate of the effect.

Very low certainty: We have very little confidence in the effect estimate: the true effect is likely to be substantially different from the estimate of effect.

${ }^{1}$ We assessed imprecision as very serious as the single identified study had a wide $95 \%$ confidence interval spanning 1.0. 


\section{B A C K G R O U N D}

See glossary of terms in Appendix 1.

\section{Description of the condition}

The oesophagus is a muscular tube that acts as a conduit between the throat and stomach. It begins at the end of the pharynx, travels through the neck and thorax, and finishes in the abdomen at the stomach. The oesophagus is between $18 \mathrm{~cm}$ and $25 \mathrm{~cm}$ in length and comprises skeletal muscle proximally, smooth muscle distally, and a mixture in its central portion (Gatzoulis 2009). Boluses of swallowed food are moved along this muscular tube by coordinated waves of contractility, called peristalsis. Food or other material can become 'impacted' in the oesophagus, resulting in partial or total oesophageal obstruction. Many of these impactions resolve spontaneously and therefore never present to healthcare professionals (Liu 2012). The remainder may present acutely to hospital emergency departments, with subsequent referral on to ear, nose, and throat (ENT) surgeons or gastroenterologists for further management.

Non-organic oesophageal foreign bodies, or organic food boluses that have hard or sharp components (e.g. bone), pose a significant risk of perforating the oesophageal wall (Barabino 2015; Mezzetto 2016; Park 2016). As such, they are managed differently as they require immediate removal via rigid or flexible oesophagoscopy. Soft food boluses impacted in the oesophagus are not considered to pose this same immediate risk and so may be subjected to 'conservative' strategies to encourage disimpaction, aiming to avoid definitive endoscopic management. These soft food bolus impactions were the focus of this review.

Any delay in disimpaction may expose the patient to potential harm. Being unable to swallow causes distress and discomfort and can rapidly lead to dehydration, as secretions are not resorbed and normal enteral nutrition is prevented. Additionally, the patient is at risk of aspirating these substances into the tracheobronchial system, placing them at risk of pneumonia (Loh 2000). Finally, the bolus itself may also cause local trauma to the adjacent oesophageal mucosa. This local pressure effect may cause inflammation, progressing to ischaemia, perforation, and mediastinitis (Liu 2012). This carries a mortality approaching $100 \%$ if not treated promptly (Bladergroen 1986). As such, timely disimpaction of these soft food boluses may be needed to prevent serious sequelae.

\section{Description of the intervention}

An endoscopic procedure known as oesophagoscopy is considered definitive management for persistent cases of impaction. The lumen of the oesophagus is visualised, and the bolus is either advanced into the stomach or retrieved through the mouth. This may be performed with either a flexible or rigid endoscope, both of which are associated with potentially serious complications (Ferrari 2018; Wennervaldt 2012). The American Society for Gastrointestinal Endoscopy recommends definitive management of the oesophageal food bolus within 24 hours wherever possible, to prevent complications from delayed disimpaction (Ikenberry 2011; Loh 2000; Park 2004). Consequently, a number of 'conservative' treatments and strategies are employed in an attempt to avoid the need for endoscopic intervention within this early period. This may involve a simple period of observation, otherwise known as 'watchful waiting'. Further to this, there are a number of more active treatments that are commonly used. These may be delivered parenterally, having their effects on the tissues of the oesophagus via the blood, or enterally, having a direct effect within the lumen of the oesophagus.

\section{How the intervention might work}

\section{Watchful waiting}

Observation, or watchful waiting, aims to allow more time for the bolus to pass spontaneously. The muscle fibres surrounding the bolus may be in spasm, and so a period of observation will allow time for them to relax spontaneously and the bolus to pass into the stomach through normal processes. Watchful waiting aims to avoid the need for any form of intervention, whether endoscopic, enteral, or parenteral, thereby avoiding any associated side effects or complications. However, there may be increased risks from this delaying strategy, including immediate or late perforation if the bolus remains impacted for too long (Loh 2000; Park 2004).

\section{Parenteral treatments}

Parenteral treatments may be administered subcutaneously, intramuscularly, or intravenously. They are proposed to relax the musculature of the oesophageal wall, thereby allowing the impacted bolus to pass into the stomach. Depending on the level of impaction within the oesophagus, these medications may target smooth muscle or skeletal muscle. Commonly used medications are highlighted below.

Benzodiazepines increase the effects of gamma amino butyric acid (GABA) at the GABA-A receptor, reducing the excitability of neurons. Amongst other effects, this can relax the skeletal muscle in the proximal oesophagus. Benzodiazepines must be used cautiously due to their potentially serious side effect of central respiratory depression (Griffin 2013).

Hyoscine butylbromide is an anticholinergic agent, which inhibits parasympathetic actions on smooth muscle, resulting in relaxation and dilatation. It may be given subcutaneously, intramuscularly, or intravenously and is most commonly administered four times daily (Tytgat 2007). There are no serious side effects commonly encountered with hyoscine butylbromide.

Glucagon is a single-chain polypeptide hormone that works to raise serum glucose level and also relax smooth muscle in the lower oesophageal sphincter and distal oesophagus. It may be given subcutaneously, intramuscularly, or intravenously (Colon 1999). Side effects include hyperglycaemia, and caution should be exercised with use in diabetic patients.

Calcium channel blockers inhibit the entry of calcium ions into smooth muscle cells, reducing their ability to contract and so allowing dilatation (Katz 1986). They are used primarily in cardiovascular disease, and so common potentially serious side effects include arrhythmias and hypotension. Calcium channel blockers must be used with caution alongside other cardiovascular drugs.

\section{Enteral treatments}

Enteral treatments work within the oesophageal lumen, directly on the bolus itself. The patient may take them orally or they may be administered through the nose with the help of a suitable conduit. 
Gas-forming or effervescent agents, such as carbonated drinks, may be drunk by the patient. The proposed mechanism of action is to create increased pressure between the obstruction and cricopharyngeal sphincter above, propelling the food bolus inferiorly towards the stomach (David 2019).

Pineapple juice contains bromelain, which is a proteolytic enzyme that aims to soften and dissolve the food bolus (Thomas 2004). Papain is derived from papaya fruit and has a similar proteolytic mechanism of action. The practice of enzymatic disimpaction has largely ceased because of the non-selective nature of the digestive agents, affecting not only the foreign body but also the oesophageal wall, which may increase the risk of subsequent perforation (Morse 2016). Once softened, the impacted bolus may loosen, and normal peristaltic actions may resume.

Non-endoscopic instrumentation of the bolus may also be attempted, often through the nasal route to avoid stimulating a gag reflex in the patient. A nasogastric (NG) tube may be passed to interact with the bolus, without visualisation. The NG tube may also be used to deliver liquids, such as effervescent or proteolytic agents, or gas, such as room air, proximal surface of the bolus (Goldman 1994; Marano 2016). Blind instrumentation of an obstructed oesophagus may pose a perforation risk, particularly once it has been traumatised by an impacted food bolus.

\section{Why it is important to do this review}

Timely management of oesophageal food bolus impaction is essential to prevent life-threatening complications, as outlined previously. Prevailing clinical consensus suggests that nonendoscopic treatments and strategies should be used initially to help minimise the exposure to risk from endoscopic intervention. However, there is no robust evidence as to which methods should be employed, and for how long, before undergoing endoscopy. Endoscopic interventions have the potential to bring about faster resolution of the impaction, but the procedure carries potential risks and complications. Safe and effective treatments that help to avoid endoscopic intervention would therefore be justified.

\section{OB JECTIVES}

To evaluate the efficacy of non-endoscopic conservative treatments in the management of soft food boluses impacted within the oesophagus.

\section{METHODS}

\section{Criteria for considering studies for this review}

\section{Types of studies}

We considered randomised controlled trials that compared conservative (non-endoscopic) treatments for impacted oesophageal food boluses against other conservative (nonendoscopic) treatments, placebo, or watchful waiting.

\section{Types of participants}

\section{Inclusion criteria}

- People of any age.

- History of acute soft food bolus ingestion.

- History suggestive of oesophageal impaction. This may manifest as complete aphagia, suggesting a proximal blockage, or with delayed regurgitation, which is more suggestive of a distal oesophageal impaction.

- Reporting the incidence of disimpaction (confirmed radiologically or clinically by return to oral diet) without the need for endoscopic intervention, i.e. food bolus disimpaction without the need for oesophagoscopy.

\section{Exclusion criteria}

- History of sharp- or solid-object ingestion, whether food derived, such as animal bone, or 'foreign', such as dentures or coins.

\section{Types of interventions}

We considered the following:

- all non-endoscopic treatments, as outlined above. These are broadly divided into enteral treatments, parenteral treatments, and watchful waiting;

- combinations of treatments, providing the allocated management did not include endoscopy;

- all doses and dosing regimens;

- all relevant parenteral routes: subcutaneous, intramuscular, and intravenous;

- all comparisons of the above treatments, including comparisons with placebo.

\section{Types of outcome measures}

\section{Primary outcomes}

- Incidence of disimpaction, without the need for endoscopic intervention, at any point prior to endoscopic intervention.

- Serious adverse events (including aspiration, perforation, and death).

\section{Secondary outcomes}

- Adverse events (including side effects and complications from enteral and parenteral treatments and any sequelae during or as a result of watchful waiting).

- Time to disimpaction, without the need for endoscopic intervention.

- Patient satisfaction scores for different treatment strategies.

- Length of hospital stay.

- Re-presentation with soft food bolus impaction within follow-up period of the study.

\section{Search methods for identification of studies}

We conducted systematic searches of the published and unpublished literature to identify randomised controlled trials relevant to our review question. There were no restrictions related to year of publication, publication status, or language of publication, and we would have arranged translations if appropriate. If further data were required to report the primary outcomes, we would have sought clarification from the study authors directly.

\section{Electronic searches}

We searched the following electronic databases to identify relevant studies. We last conducted the searches on 18 August 2019. 
- Cochrane Central Register of Controlled Trials (CENTRAL) (searched via Ovid; up to Issue 7, 2019) (Appendix 2).

- MEDLINE (searched via Ovid; 1946 to 18 August 2019) (Appendix 3).

- Embase (searched via Ovid; 1974 to 18 August 2019) (Appendix 4).

- CINAHL (Cumulative Index to Nursing and Allied Health Literature) (searched via EBSCO; 1982 to 18 August 2019).

\section{Searching other resources}

We searched the reference lists of the articles retrieved, including those of review articles. We attempted to contact authors of relevant studies to ask them to identify any other published and unpublished studies. We searched for errata or retractions of eligible studies at www.ncbi.nlm.nih.gov/pubmed on 21 August 2019.

\section{Data collection and analysis}

\section{Selection of studies}

Two review authors ( $\mathrm{JH}$ and NS) independently screened the titles and abstracts of studies identified by the above search strategy. We identified and excluded duplicates, and then coded unique articles as either 'retrieve' (eligible or potentially eligible/unclear) or 'do not retrieve' if clearly irrelevant. For articles coded as 'retrieve', we obtained the full-text publication. Two review authors ( $\mathrm{JH}$ and NS) then independently assessed the text to identify studies for inclusion. We excluded ineligible studies, recording the reasons for exclusion in the Characteristics of excluded studies tables. Any disagreements were resolved through discussion or in consultation with a third review author (JS). Had we identified multiple reports of the same study, we would have collated these, so that each study, rather than each report, formed the unit of interest in the review. The selection process is recorded in a PRISMA flow diagram (Figure $1)$. 
Figure 1. PRISMA flow diagram of study selection process.

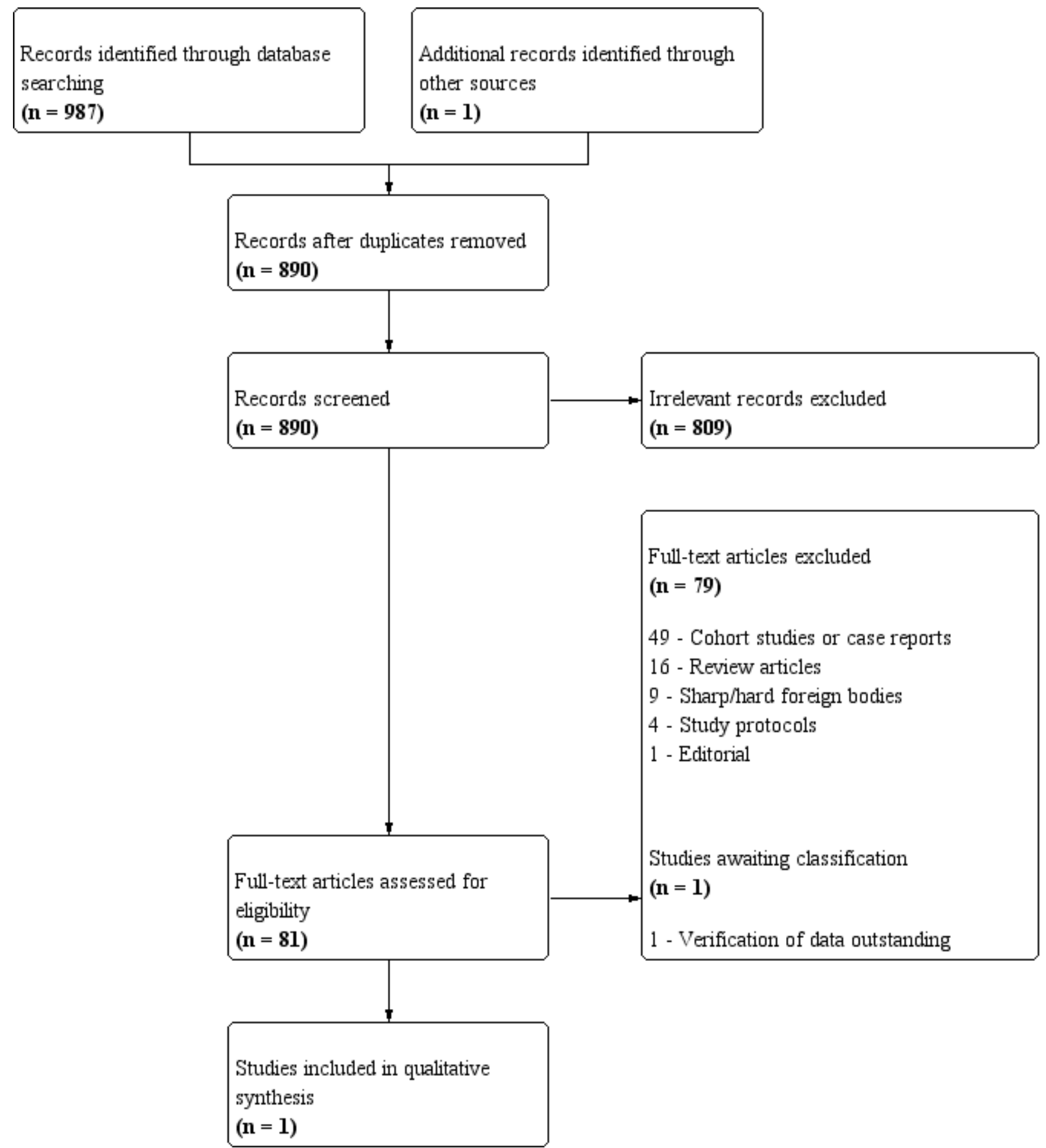

\section{Data extraction and management}

We used a standard data collection form for study characteristics and outcome data that was pre-piloted and adapted as required. Two review authors (JH and NS) independently extracted study characteristics. We attempted to extract the following study characteristics.
- Methods: study design, total duration study and run-in, number of study centres and location, study setting, withdrawals, date of study.

- Participants: N, mean age, age range, gender, severity of condition, diagnostic criteria, baseline lung function, smoking history, inclusion criteria, exclusion criteria.

- Interventions: intervention, comparison, concomitant medications, excluded medications. 
- Outcomes: primary and secondary outcomes specified and collected, and time points reported.

- Notes: funding for study, notable conflicts of interest of study authors.

Two review authors (JH and NS) independently extracted outcome data from the included studies (for details see Characteristics of included studies). No outcome data were reported in an unusable way. Any disagreements would have been resolved by consensus or by involving a third review author (JS); this was not required as there were no disagreements. One review author $(\mathrm{JH})$ entered the data from the data collection form into the Review Manager 5 file (Review Manager 2014). A second review author (NS) verified this for accuracy.

\section{Assessment of risk of bias in included studies}

Two review authors (JH and NS) independently assessed risk of bias using the criteria outlined in the Cochrane Handbook for Systematic Reviews of Interventions (Higgins 2011). There were no disagreements between review authors requiring arbitration by a third review author. We assessed bias for the following domains.

- Random sequence generation.

- Allocation concealment.

- Blinding of participants and personnel.

- Blinding of outcome assessment.

- Incomplete outcome data.

- Selective outcome reporting.

- Other bias.

We graded each potential source of bias as either high, low, or unclear and have provided quotes from the study report, together with a justification for our judgement, in the 'Risk of bias' table. Had information on risk of bias related to unpublished data or correspondence with a trial author, we would have noted this in the 'Risk of bias' table. When considering treatment effects, we assessed the risk of bias for the studies that contributed to that outcome.

\section{Assessment of bias in conducting the systematic review}

We conducted the review in accordance with the published protocol, reporting any deviations from it in the Differences between protocol and review section.

\section{Measures of treatment effect}

We analysed dichotomous data as risk ratios. We would have reported continuous data as mean difference or standardised mean difference. We would have summarised time-to-event outcomes using hazard ratios. We would have undertaken meta-analysis if this were meaningful, that is if the treatments, participants, and the underlying clinical question were similar enough for pooling to make sense.

We did not encounter any reporting of medians and interquartile ranges, which may have suggested skewed data, but would have reported this and considered its implications.

Had we encountered multiple study arms in a single study, we would have included only the relevant arms. If the same metaanalysis needed two comparisons, we would have halved the control group to avoid double counting.

\section{Unit of analysis issues}

We identified no non-standard parallel group random allocation study designs. Had we identified cross-over studies, we would only have considered the results from the first phase of the study, prior to cross-over.

\section{Dealing with missing data}

We attempted to contact study investigators to clarify key study characteristics and to obtain missing outcome data. Where appropriate, we would have followed intention-to-treat principles.

\section{Assessment of heterogeneity}

We would have used the $\mathrm{I}^{2}$ statistic to measure heterogeneity amongst the studies in each analysis (Higgins 2003). In the case of substantial heterogeneity, we would have performed subgroup analysis.

\section{Assessment of reporting biases}

Had we identified more than 10 studies for any individual parameter, we would have produced a funnel plot to explore potential publication bias. Sensitivity analysis for missing data was not required.

\section{Data synthesis}

For quantitative analysis, we would have performed a metaanalysis using Review Manager 5, Review Manager 2014, and a random-effects model (Deeks 2011).

\section{'Summary of findings' table}

We created a 'Summary of findings' table for the outcome disimpaction of the soft food bolus prior to endoscopic intervention.

We used the five GRADE considerations (study limitations, consistency of effect, imprecision, indirectness, and publication bias) to assess the certainty of the body of evidence for this outcome. Two review authors performed the GRADE assessment (JH and NS), reaching a score by consensus and not requiring arbitration by a third review author (JS).

We used the methods and recommendations described in Section 8.5 and Chapter 12 of the Cochrane Handbook for Systematic Reviews of Interventions (Higgins 2011), employing GRADEpro software (GRADEpro 2015). We justified decisions to downgrade or upgrade the certainty of the evidence in footnotes.

\section{Subgroup analysis and investigation of heterogeneity}

Had it been applicable, we would have performed subgroup analysis of the type of conservative treatment, grouped by substance type (irrespective of dose, regimen, or route) or watchful waiting, with the aim of determining if any single enteral or parenteral treatment outperformed another, including watchful waiting. We would have used only the primary outcome measures.

\section{Sensitivity analysis}

Had it been required, we would have performed a sensitivity analysis including only studies at low risk of bias for all domains outlined in the Assessment of risk of bias in included studies section. 


\section{Reaching conclusions}

We based conclusions on the findings from this review. We planned to outline implications for both practice and research.

\section{Summary of findings and assessment of the certainty of the evidence}

\section{RES ULT S}

\section{Description of studies}

See Characteristics of included studies, Characteristics of excluded studies, and Characteristics of studies awaiting classification for further details.

\section{Results of the search}

We identified a total of 987 records through the electronic searches, and one further record through the peer review process. We excluded 98 duplicate records, leaving 890 unique records. We excluded 809 clearly irrelevant records after title and abstract assessment, retrieving the full texts of the remaining 81 records for further assessment. We excluded 79 records and included one randomised controlled trial that met the inclusion criteria. There were no ongoing studies and one study awaiting classification, after the paper was provided by a reviewer but verification of the data was outstanding. The process of study selection is outlined in Figure 1.

\section{Included studies}

Tibbling 1995 is a randomised, placebo-controlled, doubleblinded, parallel-group trial including 43 participants, co-ordinated from University Hospital, Linköping, Sweden. Three other Swedish hospitals participated (University Hospital Uppsala and the central hospitals of Jönköping and Norrköping), though the recruitment rates at individual sites are not described. Participants were randomised to receive either intravenous diazepam and glucagon or identically appearing placebos. The primary outcome was disimpaction of the foreign body. It was not stated how the disimpaction was assessed, though radiological confirmation was required for inclusion in the study. The effects of the drugs were followed for one hour before the initial outcomes were recorded. Disimpactions occurring after one hour were also recorded, though no standardised time point for this assessment was declared. There was no indication of any a priori power calculation, but the authors report that their intention was to recruit 40 participants. The study was conducted over a two-year period and published in 1995 in the journal Dysphagia (Springer-Verlag New York Inc).

\section{Excluded studies}

We identified one other randomised trial evaluating oesophageal impaction (Mehta 2001), which we excluded as it looked only at coin impactions. Reasons for exclusion of the majority of the other studies that passed initial screening were retrospective/ prospective observational cohort studies, or limited case reports, and not experimental trials with randomisation. For further details see Characteristics of excluded studies.

\section{Risk of bias in included studies}

We assessed the risk of bias in the included study, Tibbling 1995, using Cochrane's 'Risk of bias' tool as described in the Cochrane Handbook for Systematic Reviews of Interventions (Higgins 2011).

\section{Allocation}

Tibbling 1995 does not specify the randomisation ratio, but it is assumed to be 1:1. Randomisation was carried out centrally in advance by a pharmacologist who retained the code until recruitment had completed.

\section{Blinding}

Both active substances and placebos in Tibbling 1995 were clear, colourless liquids distributed in identical glass ampoules from a central pharmacy. Investigators and participants were thus blinded as to the nature of the substances administered. There is no indication that the concealment was broken at any point during the trial for any participants.

\section{Incomplete outcome data}

Results are presented for 43 participants in Tibbling 1995. There is no indication that any participants were recruited and randomised but failed to complete the study. There was slight imbalance in the recruited groups, with 24 receiving active substances and 19 receiving placebos.

\section{Selective reporting}

Tibbling 1995 appears to have presented outcomes for all 43 randomised participants. There was no declared intention to perform subgroup analysis, and no subgroup analysis was reported.

\section{Other potential sources of bias}

No baseline characteristics were presented for comparison of the active substances and placebo group in the Tibbling 1995 publication. Confirmation that the groups, although randomly allocated, were equivalent, would have been reassuring. Differences in comorbidities, such as oesophageal strictures and hiatus hernias, could have influenced the likelihood of a food bolus clearing spontaneously.

Data on the time until endoscopy was performed for the comparable groups were not provided. A delay could have allowed more time for the bolus to clear spontaneously, thereby influencing the success rates seen between the two groups if significantly different.

\section{Effects of interventions}

See: Summary of findings 1 Diazepam and glucagon compared to placebo for the management of impacted food bolus in the oesophagus

See Summary of findings 1 for the main comparison.

\section{Primary outcome measures}

\section{Disimpaction}

The only data available were from the Tibbling 1995 publication of 43 participants. The rates of disimpaction for the active substance and placebo groups were $37.5 \%(n=9 / 24)$ and $31.6 \%(n=6 / 19)$, respectively (risk ratio $1.19,95 \%$ confidence interval 0.51 to 2.75 , $P=0.69$ ). It was not stated how disimpaction was measured, radiologically or clinically. The effects of the drugs were assessed after one hour of the treatments being administered. If the food bolus was still impacted, then the participant was prepared for 
oesophagoscopy under general anaesthetic. Within this initial hour four participants disimpacted across both groups. An additional 11 participants were said to have subsequently disimpacted and so did not undergo endoscopy. The trial methodology did not standardise the time at which the endoscopy was intended to be performed. As such, we are not able to comment further on the timeframe for these later disimpactions as no relevant data were presented. We attempted to contact the study authors for clarification on this point but did not received a response.

For the 15 participants who did not undergo oesophagoscopy, the criteria for confirmation of disimpaction was not reported. In 26 of the 28 participants undergoing oesophagoscopy, an impacted foreign body was extracted. It is not reported if the two remaining participants had the bolus identified at the time of the procedure. It is therefore possible that the two participants had a bolus present at the time of the procedure that was then advanced into the stomach, rather than being extracted via the mouth, or if there was in fact no bolus present, implying that it had passed prior to endoscopy, and the procedure could have been considered unnecessary. With only 43 participants randomised in the trial, these two cases could have significantly influenced the success rate if they were both in the same treatment group.

\section{Serious adverse events}

No incidence of aspiration, perforation, or death was reported as resulting from either the conservative management or the endoscopic intervention (Tibbling 1995). Of note, it is not reported whether the oesophagoscopy was performed with flexible or rigid instruments.

\section{Secondary outcome measures}

Tibbling 1995 reported adverse events in 3 of the 24 participants receiving active substances: 2 experienced a burning sensation at the injection site, and 1 experienced hiccups. It was not reported which agent caused which side effect(s). Only 5 minutes were allocated between the two drugs being administered, and so attributing cause and effect may have been impossible regardless.

Tibbling 1995 did not report the time for the impaction to clear. The only available data were that 3 of the 24 participants receiving active substances and 1 of the 19 participants receiving placebos were reported to have disimpacted within one hour of administration.

Patient satisfaction scores, length of stay, and re-presentation to hospital were not reported.

\section{DISCUSSION}

\section{Summary of main results}

Soft food bolus impaction in the oesophagus is a frequently encountered condition in emergency departments around the world. A variety of non-procedural interventions are used to manage the condition and are reported in the literature. Despite this, there is a paucity of randomised trials on the topic, with only a single study addressing the issue identified in this review (Tibbling 1995). Based on this study, there is uncertainty as to the effects of active substances on the rate of disimpaction of oesophageal soft food boluses, when compared with placebo. There were insufficient data to comment on serious adverse events of any treatment regimen considered in this review.

\section{Overall completeness and applicability of evidence}

The single identified trial assessed two intravenous medications commonly used in the management of impacted oesophageal soft food boluses, namely diazepam and glucagon. Both of these drugs were administered to each participant randomised to the active intervention group. As such, we could not assess the efficacy of either substance individually.

We identified no eligible studies addressing other parenteral treatments. Similarly, we identified no eligible studies investigating enteral treatments. Consequently, the completeness of evidence addressing the treatments within the scope of this review is low.

The evidence identified here is applicable to adult patients, without a history of oesophageal stricture, presenting to emergency departments with an impaction history of less than two days. However, the generalisability to an international population is limited due to the contribution from only a single country, and the small sample size means we have low confidence that this is representative of even that population.

\section{Quality of the evidence}

The overall certainty of the evidence contributing to the main outcome measure of disimpaction was low. The effect size was not significant, and the $95 \%$ confidence interval was wide, reflecting the low precision of the findings in the single contributing study. We identified no evidence for other outcome measures.

We did not identify any incomplete or unreported trials in the review process, and so we feel that the risk of reporting bias and publication bias for this topic is low.

\section{Potential biases in the review process}

The protocol was published prior to the start of the formal review process. We feel that the search strategy was robust enough to have identified all potentially contributory evidence. At least two review authors were involved in the screening and identification of relevant studies and the extraction and analysis of data. All four review authors were involved in writing and approving the manuscript through consensus. As such, we feel the opportunity to introduce bias into the review process has been limited.

\section{Agreements and disagreements with other studies or reviews}

There are no other systematic reviews and meta-analyses in the literature that address this topic and consider only randomised controlled trials. There are numerous reviews and articles reporting the findings of observational studies, but none considering only experimental studies that are directly comparable.

It is not possible to comment on concordance of individual studies within the literature as only a single randomised trial was identified. 


\section{AUTHORS' CONCLUSIONS}

\section{Implications for practice}

There is currently inadequate data to recommend the use of any conservative treatments in the management of oesophageal soft food bolus impaction. The overall certainty of the evidence is low, with only a single, small randomised trial contributing to this assessment.

There are potentially serious side effects and complications from the treatments currently used to manage soft food bolus impaction, as well as potentially serious consequences from delaying disimpaction with a watchful waiting strategy. This review has identified insufficient evidence to adequately comment on the adverse effects of any proposed management strategy. Caution should be exercised when using any of the treatments considered in this review, including intentional delay of definitive endoscopic management.

\section{Implications for research}

Significantly more experimental studies are needed before this review question can be adequately addressed. All current management strategies risk exposure of patients to potential harm, whether that be from the treatments themselves, or from any delay in impacted bolus being cleared. The single randomised controlled trial identified by this review has too few participants to adequately comment on the effectiveness of the interventions (diazepam and glucagon) or the effectiveness of watchful waiting or placebo. Future studies should consider randomising participants at the time of presentation to either a definitive endoscopic procedure, or a conservative management strategy including observation, enteral and parenteral treatments. This will allow adequate assessment of both the efficacy of the treatments and of any adverse events resulting from delay in treatment or definitive endoscopic management itself.

\section{ACKNOWLEDGEMENTS}

We acknowledge the help and support of the Cochrane Upper Gastrointestinal and Pancreatic Diseases Group. We thank the following editors who provided comments to improve the protocol: Sarah Rhodes and Grigorios Leontiadis, and to Deirdre Walshe for copy editing the protocol.

We thank the following reviewers who commented on the review: Luigi Bonavina, Sreeshyla Basavaraj, Marilyn Walsh, Sarah Rhodes (editor) and Paul Moayyedi (editor), and to Lisa Winer for copy editing the review.

The search strategies were designed by Yuhong Yuan (Information Specialist at the Cochrane Upper Gastrointestinal and Pancreatic Diseases Group). 


\section{REFERE N CES}

\section{References to studies included in this review}

Tibbling 1995 \{published data only\}10.1007/BF00440084 Tibbling L, Bjorkhoel A, Jansson E, Stenkvist M. Effect of spasmolytic drugs on esophageal foreign bodies. Dysphagia 1995;10:126-7. [DOI: 10.1007/BF00440084]

\section{References to studies excluded from this review}

Al-Haddad 2006 \{published data only\}

Al-Haddad M, Ward EM, Scolapio JS, Ferguson DD, Raimondo M. Glucagon for the relief of esophageal food impaction: does it really work? Digestive Diseases and Sciences 2006;51:1930-3.

Anderson 2007 \{published data only\}

Anderson R, Lee J. Buscopan for oesophageal food bolus impaction. Emergency Medicine Journal 2007;24:360-1.

\section{Arora 2009 \{published data only\}}

Arora S, Galich P. Myth: Glucagon is an effective first-line therapy for esophageal foreign body impaction. Canadian Journal of Emergency Medicine 2009;11:169-71.

\section{Basavaraj 2005 \{published data only\}}

Basavaraj S, Penumetcha KR, Cable HR, Umapathy N. Buscopan in oesophageal food bolus: is it really effective? European Archives of Oto-Rhino-Laryngology 2005;262:524-7.

\section{Bekkerman 2016 \{published data only\}}

Bekkerman M, Sachdev AH, Andrade J, Twersky Y, Iqbal S. Endoscopic management of foreign bodies in the gastrointestinal tract: a review of the literature. Gastroenterology Research \& Practice 2016;2016:8520767.

Bell 1988 \{published data only\}

Bell AF, Eibling DE. Nifedipine in the treatment of distal esophageal food impaction. Archives of Otolaryngology - Head \& Neck Surgery 1988;114:682-3.

\section{Bodkin 2016 \{published data only\}}

Bodkin RP, Weant KA, Baker Justice S, Spencer MT, Acquisto NM. Effectiveness of glucagon in relieving esophageal foreign body impaction: a multicenter study. American Journal of Emergency Medicine 2016;34:1049-52.

\section{Borges 2014 \{published data only\}}

Borges AA, de Oliveira Lemme EM, Abrahao LJ, Madureira D, Andrade MS, Soldan M, et al. Pneumatic dilation versus laparoscopic Heller myotomy for the treatment of achalasia: variables related to a good response. Diseases of the Esophagus 2014;27:18-23.

\section{Brady 1991 \{published data only\}}

Brady PG. Esophageal foreign bodies. Gastroenterology Clinics of North America 1991;20:691-701.

\section{Castell 1990 \{published data only\}}

Castell JA, Dalton CB, Castell DO. Effects of body position and bolus consistency on the manometric parameters and coordination of the upper esophageal sphincter and pharynx. Dysphagia 1990;5:179-86.

\section{Chavez 2012 \{published data only\}}

Chavez Rossell M. New technique for safe removal of impacted foreign bodies in the upper gastrointestinal tract using reusable variceal "cap" (cup, cap or cylinder). Revista de Gastroenterologia del Peru: organo oficial de la Sociedad de Gastroenterologia del Peru 2012;32:150-6.

\section{Cheng 2017 \{published data only\}}

Cheng D, Lee R, Lee A, Begun J, St John A. Factors influencing the need for endoscopic intervention in esophageal meat bolus impaction: a retrospective, multicenter study. Journal of Gastroenterology and Hepatology (Australia) 2017;32:37-8.

Cronan 1980 \{published data only\}

Cronan JJ, Stein S. Glucagon therapy of esophageal food impaction. Interventional radiology. Connecticut Medicine 1980;44:77-80.

\section{Damghani 2011 \{published data only\}}

Damghani M, Halavati N, Motamedi N. Foreign body in the upper airway and oesophagus: a seven years study from Iran. JPMA: Journal of the Pakistan Medical Association 2011:61:859-62.

David 2017 \{published data only\}

David J, Backstedt DW, O'Keefe KJ, Salehpour K, Gerkin R. Effervescent granules are a safe, effective, and cost-saving initial strategy in acute esophageal food impaction. Gastrointestinal Endoscopy 2017;85(5):AB574.

Debongnie 1981 \{published data only\} Debongnie J C, Anslot P. Esophageal food impaction. Treatment by glucagon. Acta Gastroenterologica Belgica 1981;44:314-9.

\section{Dias 2017 \{published data only\}}

Dias JA, Fernandes S, Corujeira S, Trindade E, Tavares M, Murch S. Salbutamol therapy for food impaction in eosinophilic oesophagitis. Journal of Pediatric Gastroenterology and Nutrition 2017;65(4):e97.

\section{Elhamady 2017 \{published data only\}}

Elhamady HAE, Ramadan AEM, Gaafar AH, Baess AI, Hammad SW. Incidence, patterns and different modalities in extraction of aero-digestive tract foreign bodies in patients attending Alexandria main university hospital. Journal of the Egyptian Society of Cardio-Thoracic Surgery 2017;25(2):154-62.

\section{Fan 2017 \{published data only\}}

Fan Z, Dai C, Zhao L, Wang M. Endoscopic retrieval and flexible compression hemostasis for managing esophageal foreignbody ingestion with high-risk aortic injury. Digestive Endoscopy 2017;29:252.

\section{Fass 2004 \{published data only\}}

Fass R, Dekel R. Intravenous glucagon in food impaction - use it or lose it? Dysphagia 2004;19:15-7. 


\section{Ferrari 2018 \{published data only\}}

Ferrari D, Aiolfi A, Bonitta G, Riva CG, Rausa E, Siboni S, et al. Flexible versus rigid endoscopy in the management of esophageal foreign body impaction: systematic review and meta-analysis. World Journal of Emergency Surgery 2018;13:42.

\section{Ghumman 2017 \{published data only\}}

Ghumman A, Huang L, Khoo E, Stanley S, Tee D, Mclvor C. Assessment of effectiveness and safety of early versus late endoscopic intervention for the management of esophageal food bolus obstruction. Journal of Gastroenterology and Hepatology (Australia) 2017;32:40.

\section{Glauser 1979 \{published data only\}}

Glauser J, Lilja GP, Greenfeld B, Ruiz E. Intravenous glucagon in the management of esophageal food obstruction. JACEP 1979;8:228-31.

\section{Goldman 1994 \{published data only\}}

Goldman JH, Goldberg RI. Balloon removal of an impacted esophageal meat bolus. Neurologia 1994;9:9UI-24163097.

\section{Haas 2014 \{published data only\}}

Haas JM, Leo J, Vakil NB. Esophageal foreign bodies: efficacy \& safety of glucagon and endoscopy in 603 consecutive patients. Gastrointestinal Endoscopy 2014;1:AB410-1.

Hall 1988 \{published data only\}

Hall ML, Huseby JS. Hemorrhagic pulmonary edema associated with meat tenderizer treatment for esophageal meat impaction. Chest 1988;94:640-2.

\section{Haridy 2017 \{published data only\}}

Haridy J, Srinivasan A, Luber R, Philpott H. Acute food bolus presentation to emergency department and follow-up endoscopy: are we missing potential pathology? Journal of Gastroenterology and Hepatology (Australia) 2017;32:163-4.

\section{Hassan 2015 \{published data only\}}

Hassan M, Saeed A, Nabi S, Weick A, Brown KA, Pompa RL. Pharmacological management of esophageal food impactions: glucagon vs. nitroglycerin which is effective? Gastroenterology 2015;1:S809.

\section{Huang 2015 \{published data only\}}

Huang ZJ, Guffey D, Minard CG, Friedman EM. Outcomes variability in non-emergent esophageal foreign body removal: is daytime removal better? International Journal of Pediatric Otorhinolaryngology 2015;79:1630-3.

\section{Ibrahim 2019 \{published data only\}}

* Ibrahim AH, Andijani A, Abdulshakour M, Algain S, Abu Thamrah A, Ali MM, et al. What do Saudi children ingest?: A 10year retrospective analysis of ingested foreign bodies from a tertiary care center. Pediatric Emergency Care 2019 Jul 24 [Epub ahead of print]. [DOI: 10.1097/PEC.0000000000001894]

\section{Jeen 2001 \{published data only\}}

Jeen YT, Chun J, Song CW, Um SH, Lee SW, Choi JH, et al. Endoscopic removal of sharp foreign bodies impacted in the esophagus. Endoscopy 2001;33:518-22.
Kim 2016 \{published data only\}

Kim SY, Park B, Kong IG, Choi HG. Analysis of ingested foreign bodies according to age, type and location: a retrospective observational study. Clinical Otolaryngology 2016;41:640-5.

\section{Kingsbery 2017 \{published data only\}}

Kingsbery J, McNeill MB, Popov V, Gross SA. Esophageal food impaction management: a meta-analysis comparing push and pull methods. Gastrointestinal Endoscopy 2017;85(5):AB184.

Krzeski 1995 \{published data only\}

Krzeski A, Zawadowski J, Niemczyk K. latrogenic esophageal perforation. Wiadomosci Lekarskie (Warsaw, Poland: 1960) 1995;48:40-3.

\section{Langoya 2016 \{published data only\}}

Langoya CO, O'Connor A, Rembacken B. Food bolus obstruction: an experience from a large teaching hospital. Gut 2016;65:A224.

\section{Lee 2005 \{published data only\}}

Lee J, Anderson R. Best evidence topic report. Proteolytic enzymes for oesophageal meat impaction. Emergency Medicine Journal 2005;22:122-3.

\section{Leopard 2011 \{published data only\}}

Leopard D, Fishpool S, Winter S. The management of oesophageal soft food bolus obstruction: a systematic review. Annals of the Royal College of Surgeons of England 2011;93:441-4.

\section{Lorrains 2015 \{published data only\}}

Lorrains J. BET 1: use of glucagon for oesophageal food bolus impaction. Emergency Medicine Journal 2015;32:85-8.

Louie 2005 \{published data only\}

Louie JP, Alpern ER, Windreich RM. Witnessed and unwitnessed esophageal foreign bodies in children. Pediatric Emergency Care 2005;21:582-5.

Maglinte 1995 \{published data only\}

Maglinte DDT, Chernish SM, Kelvin FM, Lappas JC. Pharmacoradiologic disimpaction of esophageal foreign bodies: review and recommendation. Emergency Radiology 1995;2:151-7.

Maini 2001 \{published data only\}

Maini S, Rudralingam M, Zeitoun H, Osbourne JE. Aspiration pneumonitis following papain enzyme treatment for oesophageal meat impaction. Journal of Laryngology \& Otology 2001;115:585-6.

\section{Mazzadi 1998 \{published data only\}}

Mazzadi S, Salis GB, Garcia A, Iannicillo H, Fucile V, Chiocca JC. Foreign body impaction in the esophagus: are there underlying motor disorders? Diseases of the Esophagus 1998;11:51-4.

\section{Mehta 2001 \{published data only\}}

Mehta DI, Attia MW, Quintana EC, Cronan KM. Glucagon use for esophageal coin dislodgment in children: a prospective, 
double-blind, placebo-controlled trial. Academic Emergency Medicine 2001;8:200-3.

Monnier 2005 \{published data only\}

Monnier P. Acute food bolus impaction in the esophagus. European Archives of Oto-Rhino-Laryngology 2005;262:523.

\section{Moons 2003 \{published data only\}}

Moons LM, Kuipers EJ, Siersema PD. Acute dysphagia: often there is a readily treatable cause. Nederlands Tijdschrift voor Geneeskunde 2003;147:1713-7.

\section{Moores 1996 \{published data only\}}

Moores DWO, Ilves R. Treatment of esophageal obstruction with covered, self-expanding esophageal wallstents. Annals of Thoracic Surgery 1996;62:963-7.

\section{Morse 2016 \{published data only\}}

Morse CR, Wang H, Donahue DM, Garrity JM, Allan JS. Use of proteolytic enzymes in the treatment of proteinaceous esophageal food impaction. Journal of Emergency Medicine 2016;50:183-6.

\section{Mosca 2001 \{published data only\}}

Mosca S, Manes G, Martino R, Amitrano L, Bottino V, Bove A, et al. Endoscopic management of foreign bodies in the upper gastrointestinal tract: report on a series of 414 adult patients. Endoscopy 2001;33:692-6.

\section{Nugent 2013 \{published data only\}}

Nugent B, Lewis S, O'Sullivan JM. Enteral feeding methods for nutritional management in patients with head and neck cancers being treated with radiotherapy and/or chemotherapy. Cochrane Database of Systematic Reviews 2013, Issue 1. [DOI: 10.1002/14651858.CD007904.pub3]

\section{Odelowo 1990 \{published data only\}}

Odelowo EO, Komolafe OF. Diagnosis, management and complications of oesophageal and airway foreign bodies. International Surgery 1990;75:148-54.

\section{Ooi 2017 \{published data only\}}

Ooi M, Young E, Nguyen NQ. Effectiveness of cap-assisted device in the endoscopic management of food bolus obstruction in the upper esophagus. Journal of Gastroenterology and Hepatology 2017;32:264.

\section{Ooi 2017a \{published data only\}}

Ooi M, Young EJ, Nguyen NQ. Effectiveness of cap-assisted device in the endoscopic management of food bolus obstruction in the upper esophagus. United European Gastroenterology Journal 2017;5:A579.

\section{Ooi 2018 \{published data only\}}

Ooi M, Young EJ, Nguyen NQ. Effectiveness of a capassisted device in the endoscopic removal of food bolus obstruction from the esophagus. Gastrointestinal Endoscopy 2018;87(5):1198-203.

\section{Ooi 2018a \{published data only\}}

Ooi M, Wong S, An-Phan V, Ma W-S, Nguyen NQ. The safety and treatment outcomes of same-session endoscopic dilation of benign esophageal stricture after removal of food bolus obstruction: a prospective longitudinal study. Journal of Gastroenterology and Hepatology 2018;33:132.

Pan 2016 \{published data only\}

Pan HY, Xiang XL, Lyu SZ, Xie XP, Hou XH. A comparison of clinical characteristics between non-erosive reflux disease and reflux esophagitis. Chung-Hua Nei Ko Tsa Chih [Chinese Journal of Internal Medicine] 2016;55:510-4.

Patoulias 2016 \{published data only\}

Patoulias D, Patoulias I, Kaselas C, Feidantsis T, Farmakis K, Kalogirou M. Lower esophageal sphincter relaxation by administrating hyoscine-N-butylbromide for esophageal impaction by coin-shaped foreign bodies; prospective clinical study in pediatric population. Folia Medica Cracoviensia 2016;56:21-9.

\section{Peksa 2019 \{published data only\}}

Peksa GD, DeMott JM, Slocum GW, Burkins J, Gottlieb M. Glucagon for relief of acute esophageal foreign bodies and food impactions: a systematic review and meta-analysis. Pharmacotherapy 2019;39(4):463-72.

\section{Price 2007 \{published data only\}}

Price T, Jones SEM, Montgomery PQ. Is current UK management of oesophageal food bolus obstruction evidence based? An email survey and literature review. European Archives of OtoRhino-Laryngology 2007;264:329-35.

\section{Robbins 1994 \{published data only\}}

Robbins MI, Shortsleeve MJ. Treatment of acute esophageal food impaction with glucagon, an effervescent agent, and water. AJR: American Journal of Roentgenology 1994;162:325-8.

\section{Rodriguez-Sanchez 2013 \{published data only\}}

Rodriguez-Sanchez J, Lopez Viedma B, Verdejo Gil C, Martin Davila F, Hernandez Albujar A, Lorente Poyatos R, et al. Predictive factors of eosinophilic esophagitis in esophageal food bolus impaction. Revista de Gastroenterologia de Mexico 2013;78:5-11.

\section{Ruan 2019 \{published data only\}}

Ruan W, Shah SR, Fishman DS. Controversial aspects of pediatric foreign bodies: a single tertiary referral center experience. Gastrointestinal Endoscopy 2019;89(6):AB285-6.

Smith-Sivertsen 1985 \{published data only\} Smith-Sivertsen C, Kristensen J. Glucagon and impacted food in the esophagus. Ugeskrift for Laeger 1985;147:1855.

\section{Sodeman 2004 \{published data only\}}

Sodeman TC, Harewood GC, Baron TH. Assessment of the predictors of response to glucagon in the setting of acute esophageal food bolus impaction. Dysphagia 2004;19:18-21. 
Thomas 2005 \{published data only\}

Thomas L, Webb C, Duvvi S, Jones T, Reddy KT. Is buscopan effective in meat bolus obstruction? Clinical Otolaryngology 2005;30:183-5

\section{Tihan 2011 \{published data only\}}

Tihan D, Trabulus D, Altunkaya A, Karaca S, Cihan A, Alis H. Esophageal perforation due to inadvertent swallowing of a dental prosthesis. Turkish Journal of Gastroenterology 2011;22:529-33.

\section{Tilakaratne 2012 \{published data only\}}

Tilakaratne S, Day A, Lemberg D. Eosinophilic esophagitis and food impaction: an instructive case. Turkish Journal of Gastroenterology 2012;23:294-7.

\section{Tokar 2007 \{published data only\}}

Tokar B, Cevik AA, Ilhan H. Ingested gastrointestinal foreign bodies: predisposing factors for complications in children having surgical or endoscopic removal. Pediatric Surgery International 2007;23:135-9.

\section{Van Der Sluis 2012 \{published data only\}}

Van Der Sluis H, Van Der Wouden EJ, Moll F, Havenith MG, Meijssen M, Vecht J. Acute esophageal food bolus impaction. A prospective study. Gastroenterology 2012;1:S436.

\section{Waltzman 2006 \{published data only\}}

Waltzman M. Management of esophageal coins. Pediatric Emergency Care 2006;22:367-73.

\section{Weant 2012 \{published data only\}}

Weant KA, Weant MP. Safety and efficacy of glucagon for the relief of acute esophageal food impaction. American Journal of Health-System Pharmacy 2012;69:573-7.

Willenbring 2018 \{published data only\}

Willenbring BA, Schnitker CK, Stellpflug SJ. Oral nitroglycerin solution may be effective for esophageal food impaction. Journal of Emergency Medicine 2018;54(5):678-80.

\section{Woo 2015 \{published data only\}}

Woo SH, Kim KH. Proposal for methods of diagnosis of fish bone foreign body in the esophagus. Laryngoscope 2015;125:2472-5.

Wu 2011 \{published data only\}

Wu WT, Chiu CT, Kuo CJ, Lin CJ, Chu YY, Tsou YK, et al. Endoscopic management of suspected esophageal foreign body in adults. Diseases of the Esophagus 2011;24:131-7.

\section{Yan 2014 \{published data only\}}

Yan XE, Wang L, Zhou LY, Lin SR, Wang Y, Cheng ZR. Analysis for 171 cases of esophageal foreign bodies impacted in upper esophagus with endoscopic treatment. Beijing da Xue Xue Bao. Yi Xue Ban [Journal of Peking University. Health Sciences] 2014;46:160-4.

\section{Yuan 2019 \{published data only\}}

Yuan J, Ma M, Guo Y, He B, Cai Z, Ye B, et al. Delayed endoscopic removal of sharp foreign body in the esophagus increased clinical complications: an experience from multiple centers in China. Medicine 2019;98(26):e16146.

Zamary 2017 \{published data only\}

Zamary KR, Davis JW, Ament EE, Dirks RC, Garry JE. This too shall pass: a study of ingested sharp foreign bodies. Journal of Trauma and Acute Care Surgery 2017;82(1):150-5.

\section{Zimmers 1988 \{published data only\}}

Zimmers TE, Chan SB, Kouchoukos PL, Mirande H, Noy Y, VanLeuven B. Use of gas-forming agents in esophageal food impactions. Annals of Emergency Medicine 1988;17:693-5.

\section{References to studies awaiting assessment \\ Basavaraj 2016 \{published data only\}}

Basavaraj S, Reddy CE, Dempster J, Reddy K, Kang M. Buscopan (hyoscine butylbromide) in the management of food bolus obstruction in oesophagus: randomised controlled trial. Internet Journal of Otorhinolaryngology 2016;18(1):1-5. [http:// ispub.com/IJORL/18/1/28551]

\section{Additional references}

\section{Barabino 2015}

Barabino AV, Gandullia P, Vignola S, Arrigo S, Zannini L, Di Pietro P. Lithium battery lodged in the oesophagus: a report of three paediatric cases. Digestive and Liver Disease 2015;47(11):984-6.

\section{Bladergroen 1986}

Bladergroen MR, Lowe JE, Postlethwait RW. Diagnosis and recommended management of esophageal perforation and rupture. Annals of Thoracic Surgery 1986;42(3):235-9.

\section{Colon 1999}

Colon V, Grade A, Pulliam G, Johnson C, Fass R. Effect of doses of glucagon used to treat food impaction on esophageal motor function of normal subjects. Dysphagia 1999;14(1):27-30.

\section{David 2019}

David J, Backstedt D, O'Keefe K J, Salehpour K, Gerkin R D, Ramirez F C. Effervescent agents in acute esophageal food impaction. Diseases of the Esophagus: Official Journal of the International Society for Diseases of the Esophagus 2019;32(4). [DOI: https://doi.org/10.1093/dote/doy117]

\section{Deeks 2011}

Deeks JJ, Higgins JPT, Altman DG, Cochrane Statistical Methods Group. Chapter 9: Analysing data and undertaking metaanalyses. In: Higgins JP, Green S, editor(s). Cochrane Handbook for Systematic Reviews of Interventions Version 5.1.0 (updated March 2011). The Cochrane Collaboration, 2011. Available from handbook.cochrane.org.

\section{Gatzoulis 2009}

Gatzoulis M. Thorax. In: Standring S, Gray H, editors(s). Gray's Anatomy. Edinburgh: Churchill Livingstone Elsevier, 2009. 


\section{GRADEpro 2015 [Computer program]}

McMaster University (developed by Evidence Prime) GRADEpro GDT. Version accessed 16 August 2017. Hamilton (ON): McMaster University (developed by Evidence Prime), 2015.Available at gradepro.org.

\section{Griffin 2013}

Griffin CE 3rd, Kaye AM, Bueno FR, Kaye AD. Benzodiazepine pharmacology and central nervous system-mediated effects. Ochsner Journal 2013;13(2):214-23.

\section{Higgins 2003}

Higgins JP, Thompson SG, Deeks JJ, Altman DG. Measuring inconsistency in meta-analyses. BMJ (Clinical Research Ed.) 2003:327:557-60.

\section{Higgins 2011}

Higgins JP, Green S, editor(s). Cochrane Handbook for Systematic Reviews of Interventions Version 5.1.0 (updated March 2011). The Cochrane Collaboration, 2011. Available from handbook.cochrane.org.

\section{Ikenberry 2011}

Ikenberry SO, Jue TL, Anderson MA, Appalaneni V, Banerjee S, Ben-Menachem T, et al. Management of ingested foreign bodies and food impactions. Gastrointestinal Endoscopy 2011;73(6):1085-91.

\section{Katz 1986}

Katz AM. Pharmacology and mechanisms of action of calciumchannel blockers. Journal of Clinical Hypertension 1986;2(3 Suppl):28S-37S.

\section{Liu 2012}

Liu J, Zhang X, Xie D, Peng A, Yang X, Yu F, et al. Acute mediastinitis associated with foreign body erosion from the hypopharynx and esophagus. Otolaryngology - Head and Neck Surgery 2012;146(1):58-62.

\section{Loh 2000}

Loh K S, Tan L K, Smith J D, Yeoh K H, Dong F. Complications of foreign bodies in the esophagus. Otolaryngology - Head and Neck Surgery: Official Journal of American Academy of Otolaryngology - Head and Neck Surgery 2000;123(5):613-6.

\section{Marano 2016}

Marano L, Cecchi A, Chiodo F, Gullo F, Fiorillo P, Roncetti L, et al. An innovative fast track solution for food bolus impaction due to Jackhammer esophagus in an emergency department: the "Nitro-Push Blind Technique" case report. BMC Gastroenterology 2016;16(1):95.

\section{Mezzetto 2016}

Mezzetto L, Treppiedi E, Scorsone L, Giacopuzzi S, Perandini S, Macrì $\mathrm{M}$, et al. Thoracic aortic pseudoaneurysm after esophageal perforation and mediastinitis caused by accidental ingestion of a mutton bone: a case report on staged endoscopic and endovascular treatments. Annals of Vascular Surgery 2016;30:307.e15-9. [DOI: 10.1016/j.avsg.2015.07.025]

\section{Park 2004}

Park $\mathrm{H}$, Shin Y. Measuring case-mix complexity of tertiary care hospitals using DRGs. Health Care Management Science 2004;7(1):51-61.

\section{Park 2016}

Park IH, Lim HK, Song SW, Lee KH. Perforation of esophagus and subsequent mediastinitis following mussel shell ingestion. Journal of Thoracic Disease 2016;8(8):E693-7.

\section{Review Manager 2014 [Computer program]}

Nordic Cochrane Centre, The Cochrane Collaboration Review Manager 5 (RevMan 5). Version 5.3. Copenhagen: Nordic Cochrane Centre, The Cochrane Collaboration, 2014.

\section{Thomas 2004}

Thomas L, Low C, Webb C, Ramos E, Panarese A, Clarke R. Naturally occurring fruit juices dislodge meat bolus obstruction in vitro. Clinical Otolaryngology \& Allied Sciences 2004;29:694-7.

\section{Tytgat 2007}

Tytgat GN. Hyoscine butylbromide: a review of its use in the treatment of abdominal cramping and pain. Drugs 2007;67(9):1343-57.

\section{Wennervaldt 2012}

Wennervaldt K, Melchiors J. Risk of perforation using rigid oesophagoscopy in the distal part of oesophagus. Danish Medical Journal 2012;59(11):A4528.

\section{References to other published versions of this review Basavaraj 2008}

Basavaraj S, Boggaram G, Hicks A. Conservative interventions for the management of impacted food bolus in the oesophagus. Cochrane Database of Systematic Reviews 2008, Issue 4. [DOI: 10.1002/14651858.CD007352]

\section{Hardman 2017}

Hardman J, Sharma N, Smith J, Nankivell PC. Conservative interventions for the management of impacted food bolus in the oesophagus. Cochrane Database of Systematic Reviews 2017, Issue 10. [DOI: 10.1002/14651858.CD007352.pub2]

* Indicates the major publication for the study

\section{CHARACTERISTICS OF STUDIES}

Characteristics of included studies [ordered by study ID] 
Tibbling 1995

\section{Study characteristics}

\begin{tabular}{ll}
\hline Methods & Double-blind, parallel-group, randomised, placebo-controlled trial \\
\hline Participants & $\begin{array}{l}\text { Adults with foreign-body impaction in the oesophagus presenting to } 4 \text { Swedish ear, nose, and throat } \\
\text { (ENT) departments }\end{array}$ \\
\hline Interventions & Diazepam and glucagon \\
\hline Outcomes & Disimpaction \\
\hline Notes &
\end{tabular}

\section{Risk of bias}

\begin{tabular}{|c|c|c|}
\hline Bias & Authors' judgement & Support for judgement \\
\hline \multirow[t]{2}{*}{$\begin{array}{l}\text { Random sequence genera- } \\
\text { tion (selection bias) }\end{array}$} & Low risk & $\begin{array}{l}\text { Quote: "Randomization was made in five series of } 10 \text { by a pharmacologist at } \\
\text { the Linköping University Hospital who kept the code until all } 40 \text { patients had } \\
\text { been treated and evaluated." }\end{array}$ \\
\hline & & Comment: co-ordinated centrally \\
\hline \multirow[t]{2}{*}{$\begin{array}{l}\text { Allocation concealment } \\
\text { (selection bias) }\end{array}$} & Low risk & $\begin{array}{l}\text { Quote: "Randomization was made in five series of } 10 \text { by a pharmacologist at } \\
\text { the Linköping University Hospital who kept the code until all } 40 \text { patients had } \\
\text { been treated and evaluated." }\end{array}$ \\
\hline & & Comment: allocation was unknown until after consent and randomisation \\
\hline \multirow{2}{*}{$\begin{array}{l}\text { Blinding of participants } \\
\text { and personnel (perfor- } \\
\text { mance bias) } \\
\text { All outcomes }\end{array}$} & Low risk & $\begin{array}{l}\text { Quote: "the placebo preparations were delivered in glass ampoules of identi- } \\
\text { cal appearance." }\end{array}$ \\
\hline & & $\begin{array}{l}\text { Comment: identical, placebo-controlled ampoules. No indication that con- } \\
\text { cealment was broken during treatment or observation period. }\end{array}$ \\
\hline \multirow{2}{*}{$\begin{array}{l}\text { Blinding of outcome as- } \\
\text { sessment (detection bias) } \\
\text { All outcomes }\end{array}$} & Low risk & $\begin{array}{l}\text { Quote: "the placebo preparations were delivered in glass ampoules of identi- } \\
\text { cal appearance." }\end{array}$ \\
\hline & & $\begin{array}{l}\text { Comment: identical, placebo-controlled ampoules. No indication that con- } \\
\text { cealment was broken during treatment or observation period. }\end{array}$ \\
\hline \multirow{2}{*}{$\begin{array}{l}\text { Incomplete outcome data } \\
\text { (attrition bias) } \\
\text { All outcomes }\end{array}$} & Unclear risk & $\begin{array}{l}\text { Quote: "The foreign body disimpacted in } 38 \% \text { (9/24) of those given active sub- } \\
\text { stances and in 32\% (6/19) of those given placebo (not significant)." }\end{array}$ \\
\hline & & $\begin{array}{l}\text { Comment: outcomes recorded for all } 43 \text { participants declared as entering } \\
\text { study. Assumed complete follow-up and no attrition. }\end{array}$ \\
\hline $\begin{array}{l}\text { Selective reporting (re- } \\
\text { porting bias) }\end{array}$ & Low risk & $\begin{array}{l}\text { Comment: no subgroups to consider. Outcomes reported for all } 43 \text { partici- } \\
\text { pants. There was no a priori registration of the protocol to ensure that all in- } \\
\text { tended outcomes were reported. }\end{array}$ \\
\hline Other bias & Low risk & $\begin{array}{l}\text { No baseline characteristics presented. No breakdown of presentation/out- } \\
\text { come by site. }\end{array}$ \\
\hline
\end{tabular}

Characteristics of excluded studies [ordered by study ID] 


\begin{tabular}{|c|c|}
\hline Study & Reason for exclusion \\
\hline Al-Haddad 2006 & Cohort study or case report \\
\hline Anderson 2007 & Review \\
\hline Arora 2009 & Review \\
\hline Basavaraj 2005 & Study protocol \\
\hline Bekkerman 2016 & Review \\
\hline Bell 1988 & Cohort study or case report \\
\hline Bodkin 2016 & Cohort study or case report \\
\hline Borges 2014 & Study protocol \\
\hline Brady 1991 & Review \\
\hline Castell 1990 & Study protocol \\
\hline Chavez 2012 & Cohort study or case report \\
\hline Cheng 2017 & Cohort study or case report \\
\hline Cronan 1980 & Cohort study or case report \\
\hline Damghani 2011 & Cohort study or case report \\
\hline David 2017 & Cohort study or case report \\
\hline Debongnie 1981 & Cohort study or case report \\
\hline Dias 2017 & Cohort study or case report \\
\hline Elhamady 2017 & Cohort study or case report \\
\hline Fan 2017 & Sharp/hard foreign body \\
\hline Fass 2004 & Review \\
\hline Ferrari 2018 & Review \\
\hline Ghumman 2017 & Cohort study or case report \\
\hline Glauser 1979 & Cohort study or case report \\
\hline Goldman 1994 & Cohort study or case report \\
\hline Haas 2014 & Cohort study or case report \\
\hline Hall 1988 & Cohort study or case report \\
\hline Haridy 2017 & Cohort study or case report \\
\hline Hassan 2015 & Cohort study or case report \\
\hline
\end{tabular}




\begin{tabular}{|c|c|}
\hline Study & Reason for exclusion \\
\hline Huang 2015 & Cohort study or case report \\
\hline Ibrahim 2019 & Cohort study or case report \\
\hline Jeen 2001 & Sharp/hard foreign body \\
\hline Kim 2016 & Cohort study or case report \\
\hline Kingsbery 2017 & Review \\
\hline Krzeski 1995 & Cohort study or case report \\
\hline Langoya 2016 & Cohort study or case report \\
\hline Lee 2005 & Review \\
\hline Leopard 2011 & Review \\
\hline Lorrains 2015 & Review \\
\hline Louie 2005 & Cohort study or case report \\
\hline Maglinte 1995 & Review \\
\hline Maini 2001 & Cohort study or case report \\
\hline Mazzadi 1998 & Cohort study or case report \\
\hline Mehta 2001 & Sharp/hard foreign body \\
\hline Monnier 2005 & Editorial \\
\hline Moons 2003 & Cohort study or case report \\
\hline Moores 1996 & Cohort study or case report \\
\hline Morse 2016 & Cohort study or case report \\
\hline Mosca 2001 & Cohort study or case report \\
\hline Nugent 2013 & Review \\
\hline Odelowo 1990 & Cohort study or case report \\
\hline Ooi 2017 & Cohort study or case report \\
\hline Ooi 2017a & Cohort study or case report \\
\hline Ooi 2018 & Cohort study or case report \\
\hline Ooi 2018a & Cohort study or case report \\
\hline Pan 2016 & Cohort study or case report \\
\hline Patoulias 2016 & Sharp/hard foreign body \\
\hline
\end{tabular}




\begin{tabular}{|c|c|}
\hline Study & Reason for exclusion \\
\hline Peksa 2019 & Review \\
\hline Price 2007 & Review \\
\hline Robbins 1994 & Cohort study or case report \\
\hline Rodriguez-Sanchez 2013 & Cohort study or case report \\
\hline Ruan 2019 & Cohort study or case report \\
\hline Smith-Sivertsen 1985 & Cohort study or case report \\
\hline Sodeman 2004 & Cohort study or case report \\
\hline Thomas 2005 & Cohort study or case report \\
\hline Tihan 2011 & Sharp/hard foreign body \\
\hline Tilakaratne 2012 & Review \\
\hline Tokar 2007 & Cohort study or case report \\
\hline Van Der Sluis 2012 & Cohort study or case report \\
\hline Waltzman 2006 & Sharp/hard foreign body \\
\hline Weant 2012 & Review \\
\hline Willenbring 2018 & Cohort study or case report \\
\hline Woo 2015 & Sharp/hard foreign body \\
\hline Wu 2011 & Cohort study or case report \\
\hline Yan 2014 & Cohort study or case report \\
\hline Yuan 2019 & Sharp/hard foreign body \\
\hline Zamary 2017 & Sharp/hard foreign body \\
\hline Zimmers 1988 & Cohort study or case report \\
\hline
\end{tabular}

Characteristics of studies awaiting classification [ordered by study ID]

Basavaraj 2016

\begin{tabular}{ll}
\hline Methods & Single-blinded randomised controlled trial \\
\hline Participants & 42 \\
\hline Interventions & $\begin{array}{l}\text { Buscopan } 20 \mathrm{mg} \text { (Boehringer Ingelheim, Bracknell, UK) versus placebo (same volume of normal } \\
\text { saline: } 1 \mathrm{~mL})\end{array}$
\end{tabular}


Basavaraj 2016 (Continued)

Outcomes Disimpaction assessed by clinical staff with liquid challenge

Notes Paper provided by reviewer but verification of data outstanding.

\section{DATA AND ANALYSES}

Comparison 1. Diazepam and glucagon compared to placebo for the management of impacted food bolus in the oesophagus

\begin{tabular}{lllll}
\hline Outcome or subgroup title & $\begin{array}{l}\text { No. of } \\
\text { studies }\end{array}$ & $\begin{array}{l}\text { No. of partici- } \\
\text { pants }\end{array}$ & Statistical method & Effect size \\
\hline 1.1 Disimpaction & 1 & 43 & Risk Ratio (M-H, Random, 95\% Cl) & $1.19[0.51,2.75]$ \\
\hline
\end{tabular}

Analysis 1.1. Comparison 1: Diazepam and glucagon compared to placebo for the management of impacted food bolus in the oesophagus, Outcome 1: Disimpaction

\begin{tabular}{lccccccc} 
& \multicolumn{2}{c}{ Experimental } & \multicolumn{2}{c}{ Control } & \multicolumn{2}{c}{ Risk Ratio } & \multicolumn{2}{c}{ Risk Ratio } \\
Study or Subgroup & Events & Total & Events & Total & Weight & M-H, Random, 95\% CI & M-H, Random, 95\% CI
\end{tabular}

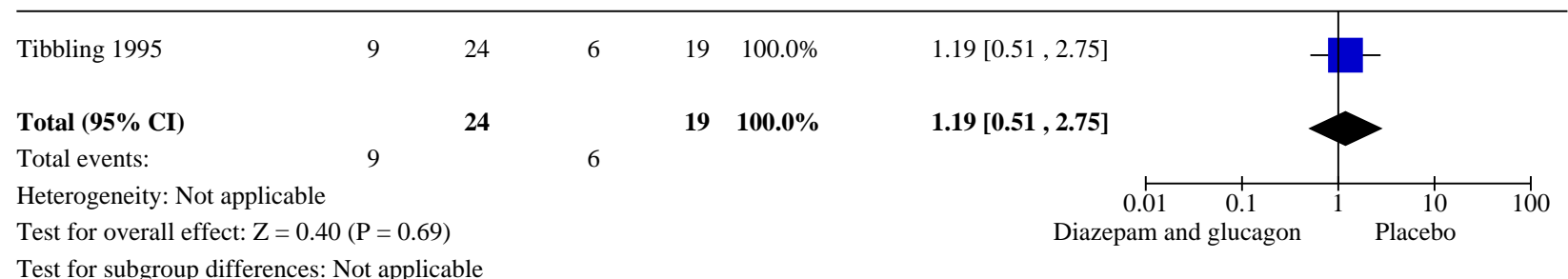

\section{AP P E N DICES}

\section{Appendix 1. Glossary of terms}

Aphagia - the loss of the ability to swallow

Arrhythmia - irregular heartbeat

Aspirating - the drawing of a foreign object (such as food) into the airway

Hyperglycaemia - an excess of glucose (a type of sugar) in the bloodstream

Hypotension - low blood pressure

Intramuscularly - administered through a muscle

Intravenously - administered through a vein (through the bloodstream)

Ischaemia - an inadequate blood supply

Lumen - the space inside a tubular structure within the body

Mediastinitis - inflammation of the tissues of the mid-chest 
Mortality - death rate

Pharynx - the cavity behind the nose and mouth

Serum - clear fluid separated from clotted blood

Regurgitation - the action of bringing up food into the mouth after it has been swallowed

\section{Appendix 2. CENTRAL search strategy}

1. exp Esophageal Stenosis/ and (exp Foreign Bodies/ or exp Food/)

2. (Steakhouse syndrome or steakhouse spasm $\left.{ }^{\star}\right) . \mathrm{mp}$.

3. ((esophag* or oesophag $\left.{ }^{\star}\right)$ and (food* or meat foreign bod $\left.{ }^{\star}\right)$ and (bolus or mass)).tw,kw.

4. ((esophag* or oesophag $\left.{ }^{\star}\right)$ and $\left(\right.$ food $^{\star}$ or meat or foreign bod b $\left.^{\star}\right)$ and (impact ${ }^{\star}$ or aphagia or block ${ }^{\star}$ or regurgit $\left.{ }^{\star}\right)$ ).tw,kw.

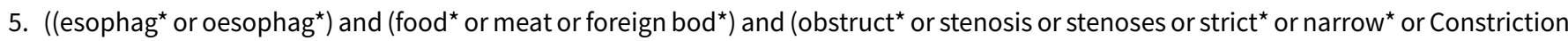
or stuck*)).tw,kw.

6. or/1-5

\section{Appendix 3. MEDLINE search strategy}

1. exp Esophageal Stenosis/ and (exp Foreign Bodies/ or exp Food/)

2. (Steakhouse syndrome or steakhouse spasm).mp.

3. ((esophag* or oesophag $\left.{ }^{\star}\right)$ and (food ${ }^{\star}$ or meat foreign bod $\left.{ }^{\star}\right)$ and (bolus or mass)).tw,kw.

4. ((esophag* or oesophag $\left.{ }^{\star}\right)$ and (food ${ }^{\star}$ or meat or foreign bod $\left.{ }^{\star}\right)$ and (impact* or aphagia or block ${ }^{\star}$ or regurgit $\left.{ }^{\star}\right)$ ).tw,kw.

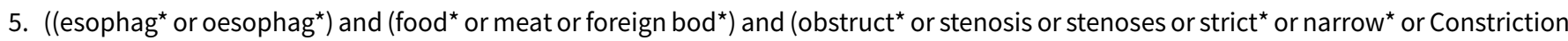
or stuck*)).tw,kw.

6. or/1-5

7. randomized controlled trial.pt.

8. controlled clinical trial.pt.

9. random*.ab.

10. placebo.ab.

11.trial.ab.

12.groups.ab.

13.drug therapy.fs.

14.or/7-13

15.exp animals/ not humans.sh.

16.14 not 15

17.6 and 16

Note:

For RCT filter we used the "Box 6.4.c: Cochrane Highly Sensitive Search Strategy for identifying randomized trials in MEDLINE: sensitivitymaximizing version (2008 revision); Ovid format". We made the following minor revision: we used "random*" instead of "randomized.ab" or "randomly.ab." to capture word variations such as "randomised, randomization, random".

\section{Appendix 4. Embase search strategy}

1. (exp esophagus obstruction/ or exp esophagus stenosis/) and (exp esophagus foreign body/ or exp food/)

2. (Steakhouse syndrome or steakhouse spasm $\left.{ }^{\star}\right) \cdot \mathrm{mp}$.

3. ((esophag* or oesophag*) and (food ${ }^{\star}$ or meat foreign bod $\left.{ }^{\star}\right)$ and (bolus or mass)).tw,kw.

4. ((esophag* or oesophag $\left.{ }^{\star}\right)$ and $\left(\right.$ food $^{\star}$ or meat or foreign bod $\left.{ }^{\star}\right)$ and (impact ${ }^{\star}$ or aphagia or block ${ }^{\star}$ or regurgit $\left.\left.{ }^{\star}\right)\right)$.tw,kw.

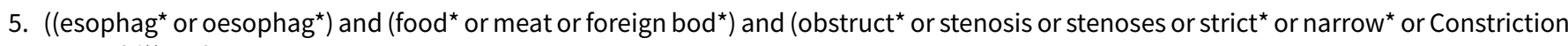
or stuck* $\left.{ }^{*}\right)$.tw,kw.

6. or/1-5

7. random:.tw.

8. clinical trial:.mp.

9. placebo:.mp.

10. double-blind:.tw.

11. or $/ 7-10$ 
12.exp animal/ not human.sh.

13.11 not 12

14.6 and 13

Note: Combined one term and two terms min difference of high sensitivity and high specificty RCT filter: https://hiru.mcmaster.ca/hiru/ hedges/All-EMBASE.htm

WHAT'S NEW

\begin{tabular}{lll}
\hline Date & Event & Description \\
\hline 20 September 2019 & New search has been performed & Submitted for editorial approval \\
\hline 3 May 2017 & Amended & Protocol revised \\
\hline
\end{tabular}

\section{HISTORY}

Protocol first published: Issue 4, 2008

Review first published: Issue 5, 2020

\section{CONTRIBUTIONS OF AUTHORS}

John Hardman: protocol development; study selection; locating and retrieving full-text articles; data extraction; GRADE assessment; writing and approving the final version of the review.

Neil Sharma: protocol development; study selection; data extraction; GRADE assessment; writing and approving the final version of the review.

Joel Smith: protocol development; writing and approving the final version of the review.

Paul Nankivell: protocol development; writing and approving the final version of the review.

\section{DECLARATIONS OF INTEREST}

$\mathrm{JH}$ : none known.

NS: none known.

JS: none known.

PN: none known.

\section{DIFFERENCES BETWEEN PROTOCOLANDREVIEW}

We made a number of terminology changes between the protocol and the main review. We broadly classified 'management' into three categories: endoscopic, non-endoscopic, and watchful waiting. Endoscopic treatment is considered the definitive treatment for oesophageal soft food bolus impaction, against which the other management types were considered.

We rephrased pharmacological and non-pharmacological agents as parenteral and enteral treatments, respectively. This allowed us to consider the previous category of 'procedural instrumentation', without visualisation of the bolus, as an enteral treatment.

The medications considered in this review were all off patent, and no novel agents were identified during the review process. As such, we did not contact any specific drug manufacturers about possible industry-funded studies.

We clarified that the primary outcome was disimpaction and the primary outcome measure could be radiological or clinical confirmation (return to oral diet).

We specified that the primary outcome of disimpaction should be time limited until the point of endoscopic intervention.

We clarified that the primary outcome was a requirement for inclusion in the review.

We clarified how we would test for heterogeneity and which statistics we would use for the comparisons for each outcome. 


\section{N D X TERMS}

\section{Medical Subject Headings (MeSH)}

Conservative Treatment [*methods]; Deglutition Disorders [etiology] [ ${ }^{\star}$ therapy]; Diazepam [*administration \& dosage]; Food [*adverse effects]; Gastrointestinal Agents [ ${ }^{*}$ administration \& dosage]; Glucagon [*administration \& dosage]; Multicenter Studies as Topic; Muscle Relaxants, Central [ ${ }^{\star}$ administration \& dosage]; Placebos [administration \& dosage]; Randomized Controlled Trials as Topic

\section{MeSH check words}

Humans 